\title{
Peri-Operative Blood Transfusion Does Not Influence Overall and Disease-Free Survival After Radical Gastrectomy for Stage II/III Gastric Cancer: a Propensity Score Matching Analysis
}

\author{
Hua Xiao ${ }^{1} \mathbb{D} \cdot$ Wu Liu ${ }^{2} \cdot$ Hu Quan ${ }^{1} \cdot$ Yongzhong Ouyang ${ }^{1}$ \\ Received: 29 January 2018 / Accepted: 7 May 2018 / Published online: 18 May 2018 \\ (C) 2018 The Author(s)
}

\begin{abstract}
Objective Whether peri-operative blood transfusions (BTF) negatively impact long-term survival after gastrectomy for gastric cancer (GC) remains controversial. The aim of this retrospective study was to investigate independent predictive factors of BTF and the potential impact of BTF on overall survival (OS) and disease-free survival (DFS) in patients who underwent radical gastrectomy for stage II/III GC.

Methods Of 1020 patients who underwent gastrectomy for stage II/III GC from November 2010 to December 2015, 231 (22.6\%) patients received BTF. The independent predictive factors of BTF were identified using univariate and multivariate analyses. Cox regression and propensity score matching (PSM) analyses of OS and DFS in patients who received BTF or not were compared. Results Multivariate analysis revealed that age, pre-operative hemoglobin levels, tumor size, operation time, combined multiorgan resection, and intra-operative blood loss were independent predictive factors for BTF. PSM analysis created 205 pairs of patients. BTF was significantly associated with decreased OS $(P=0.025)$ and DFS $(P=0.034)$ in the entire cohort before PSM. After PSM, there was no longer a significant association between BTF and OS $(P=0.850)$ or DFS $(P=0.880)$. BTF was not identified as an independent risk factor for OS or DFS by multivariate Cox regression analysis.

Conclusions The present study revealed that BTF did not influence OS and DFS after radical gastrectomy for stage II/III GC. Worse oncological outcomes were caused by clinical circumstances requiring blood transfusions, including longer operation time and advanced tumor stage, not due to BTF itself.
\end{abstract}

Keywords Gastric cancer · Gastrectomy · Transfusion · Overall survival · Disease-free survival

\section{Introduction}

The fourth most frequently occurring cancer worldwide is gastric cancer (GC) and is the second most frequent cause of cancer mortality in China, ${ }^{1,2}$ with radial surgery as the only

Electronic supplementary material The online version of this article (https://doi.org/10.1007/s11605-018-3808-8) contains supplementary material, which is available to authorized users.

Yongzhong Ouyang

oyyz@vip.sina.com

1 Department of Gastroduodenal and Pancreatic Surgery, Hunan Cancer Hospital and the Affiliated Cancer Hospital of Xiangya School of Medicine, Central South University, Changsha, China

2 Department of Gastroenterology and Urology, Hunan Cancer Hospital and the Affiliated Cancer Hospital of Xiangya School of Medicine, Central South University, Changsha, China possible curative treatment to date. Unfortunately, the majority of patients in China and Western countries are diagnosed at an advanced stage, with radical gastrectomy with D2 lymphadenectomy the recommended treatment in the guidelines for these patients in the East and West. ${ }^{3-5}$ A large number of patients with GC present with anemia on hospital admission, and furthermore, gastrectomy with lymph node dissection sometimes causes massive intra-operative blood loss even performed by experienced surgeons. ${ }^{6,7}$ Thus, blood transfusions (BTF) can be a life-saving treatment during D2 gastrectomy for advanced GC, although the need for BTF is decreasing as a result of improvements in surgical techniques and perioperative care. ${ }^{8}$ While BTF may be vital in some circumstances, there is a growing body of evidence that BTF produces adverse actions on the prognosis in GC patients who had gastrectomy operations to cure GC. ${ }^{9-12}$ Transfusionrelated immunomodulation (TRIM) and systemic inflammation have been considered to play a pivotal role in these 
detrimental effects. ${ }^{13}$ However, other scholars have argued that BTF is a confounding factor rather than a prognostic indicator because it was obviously affected by other variables. ${ }^{14-17}$ Thus, the association between BTF and oncological outcomes of GC remains controversial. We hypothesize that decreased long-term survival for GC patients who received BTF is not necessarily because of BTF, but maybe due to the extent of the patient's tumor and other prognostic factors related to BTF, such as advanced age, difficulty and duration of surgical procedure, and an advanced tumor stage. ${ }^{9}$ This question was addressed by conducting a retrospective study to investigate the association between BTF and overall survival (OS) and disease-free survival (DFS) following radical gastrectomy for stage II/III GC using the database from a high volume center in China. Multivariate Cox regression and propensity score matching (PSM) analyses were utilized to determine any links.

\section{Methods}

\section{Design and Patients}

A total of 1749 consecutive adult patients ( $\geq 18$ years old) who underwent surgery for pathologically diagnosed gastric adenocarcinoma between November 1, 2010 and December 31, 2015 in our department were screened for inclusion. Exclusion criteria and the flow chart of this study are shown in Fig. 1. In total, data from 1020 patients were analyzed in this retrospective study. Patients were categorized according to whether they received peri-operative BTF or not. The study was approved by the Affiliated Cancer Hospital of Xiangya School of Medicine ethics committee, and informed consent was obtained from all patients.

\section{Surgical Procedures and Post-Operative Management}

All operations were performed or supervised by gastrointestinal surgeons with sufficient experience of D2 or D2+ radical gastrectomy. Lymphadenectomy and gastric reconstruction were determined according to Japanese gastric cancer treatment guidelines. ${ }^{3}$ The main surgical procedures and peri-operative managements have been described in our previous study. ${ }^{18,19}$ Briefly, open procedure with D2 or D2+ lymph node dissection was the main surgical type for patients with advanced GC. Combined multi-organ resection was carried out in patients with advanced tumors suspected of invading adjacent organs or to ease dissection of lymph nodes for the purpose of R0 resection. A prophylactic antibiotic of a second- or thirdgeneration cephalosporin was administered to all patients for 3 to 5 days following the operation. Blood tests were performed at admission and 1,3,5, and 7 days after the operation. Adjuvant chemotherapy was applied in a standard manner with fluorouracil (such as S-1) and platinum (such as oxaliplatin) as the main regimens within 6 months following surgery. A few patients with massive lymph node metastasis were given adjuvant concurrent chemoradiotherapy.

\section{Definition of BTF}

Peri-operative BTF was defined as the transfusion of packed erythrocytes from the admission time to the day of discharge during hospitalization (usually 3-5 days before operation and 10-14 days thereafter). Packed erythrocytes were maintained in anti-coagulant solution containing citrate-phosphate-dextrose-adenine, whether leukocytes were depleted or not. Although transfusion was performed at the discretion of the healthcare team supervising peri-operative care, the general indication for BTF was the hemoglobin level $<80 \mathrm{~g} / \mathrm{L}$. For patients with hemoglobin level between 80 and $100 \mathrm{~g} / \mathrm{L}$, BTF was performed based on the risk factors associated with inappropriate oxygenation or hemodynamic unstability (over 65 years, with cardiovascular or respiratory diseases, oxygen consumption, rate of blood loss, and so on).

\section{Follow-Up}

All of the patients were followed up at 1 month after surgery, and then at 3-monthly periods for the first 2 years, every 6 months between year 3 and year 5, and then at 12-monthly intervals. Patients who failed to attend their follow-up visit were sent an e-mail or letter and received a phone call. Follow-up of all the patients included in the present study was completed in December 2017. Physical examination and serum tumor markers were measured at each follow-up. Computed tomography (CT) scans and/or ultrasonography were carried out at 6-month intervals during the 5 years after surgery, and endoscopy was performed at 2-year intervals. Magnetic resonance imaging (MRI), positron emission tomography, and/or biopsy was performed when distant metastasis was suspected. Chemotherapy, radiochemotherapy, molecular targeted drugs, traditional Chinese herbal drugs, and conservative treatment, either alone or in combination, were the main treatments for those with tumor recurrence. Very few patients had the opportunity to undergo resection.

\section{Data Collection and Outcomes}

Data on patient demographics, comorbidities, operative details, peri-operative morbidity and mortality, and pathological results was obtained from medical records. Each tumor was graded in accordance with the Seventh UICC (Union for International Cancer Control) TNM (tumor-lymph node-metastasis) Staging System of Gastric Cancer. ${ }^{20}$

The assessed primary outcomes were DFS and OS time. The definition of OS was the time from surgery until death 
Fig. 1 Flow chart

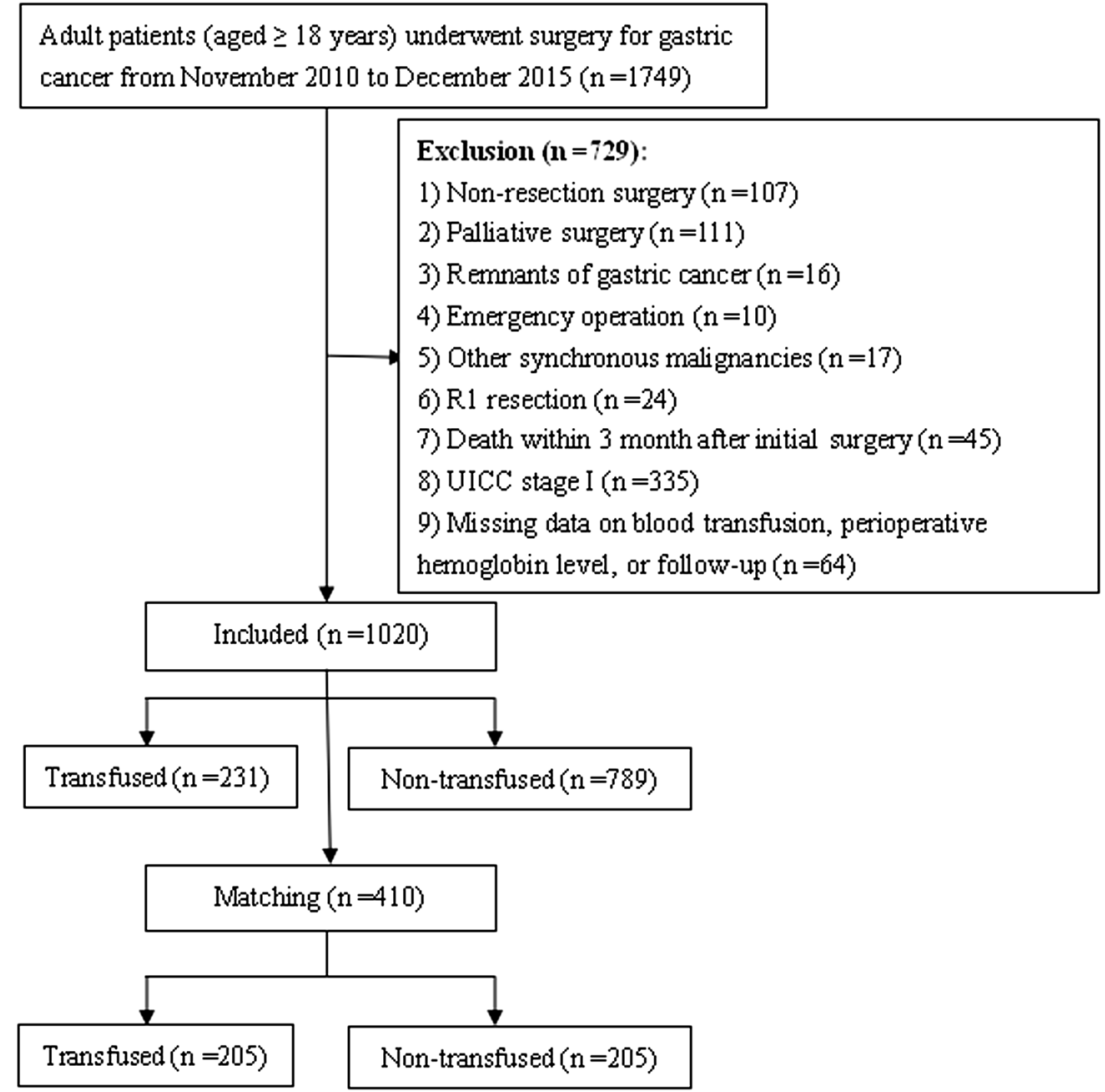

from any cause or the time of the last follow-up. DFS was defined as the period of time since surgery until recurrence of the tumor, the last follow-up, or the date when the patient died.

\section{PSM}

Patients in the BTF and non-BTF groups were classified using the PSM method described by Rubin et al., ${ }^{21}$ and was done as previously described, ${ }^{22}$ to minimize the impact of possible selective bias. Propensity scores were based on baseline variables that varied significantly between BTF and non-BTF patients in the entire cohort, including the American Society of Anesthesiologist (ASA) scores, age, body mass index (BMI), any comorbidities, type of resection, combined multi-organ resection, tumor size, and tumor location. Nearest neighbor matching was performed in a one-to-one ratio without replacement, and a caliper width with a 0.01 standard deviation (SD) was specified.

\section{Statistical Analyses}

Statistical analyses were carried out using IBM SPSS Statistics for Windows (Ver. 24, IBM Corporation, NY). Continuous data are presented as means \pm SD or medians (range), and comparisons made on data that was normally distributed using a Student's $t$ test. All categorical variables are presented as percentages and numbers, and comparisons made using a Fisher exact or $\chi^{2}$ tests. Independent risk factors for BTF were identified by univariate and multivariate regression analyses. DFS and OS were plotted using Kaplan-Meier curves, and the difference in the survival rates among of who received or did not receive BTF before and after PSM were compared using a long-rank test. Multivariate, Cox proportional, hazard regression analysis was carried out to correct the data for prognostic factors, that may have been are linked to with DFS and OS. A $P$ value $<0.05$ was considered to be statistically significant.

\section{Results}

\section{Characteristics of Patients and Blood Transfusion}

Overall, 1749 patients were identified, with 1020 with stage II/III GC who satisfied the inclusion criteria (Fig. 1). Of these patients, $231(22.6 \%)$ received BTF with a median quantity of BTF of $4 \mathrm{U}$ (range, 1.5-27.5), and the remaining 789 patients who did not receive BTF were enrolled into the non-BTF group. Of the 231 patients who were performed BTF, the overwhelming majority (206 cases, $89.2 \%$ ) were due to moderate to severe anemia (hemoglobin level $<80 \mathrm{~g} / \mathrm{L}$ ), while the remaining 25 cases $(10.8 \%)$ with a hemoglobin level between 
80 and $100 \mathrm{~g} / \mathrm{L}$ but the oxygenation was inappropriate or the hemodynamic was unstable. The clinicopathological characteristics of the entire cohort are listed in Table 1. Patient-, operation-, and tumor-related variables such as age, BMI, ASA score, pre-operative hemoglobin levels, type of resection, combined multi-organ resection, splenectomy, intraoperative blood loss, operation time, tumor size, and tumor location varied significantly between the two groups (all $P<$ 0.05 ). In the cohort of patients, peri-operative morbidities (defined as Clavien-Dindo classification II or greater ${ }^{23}$ ) were significantly increased in the BTF group (19.0\%) compared with the non-BTF group $(7.2 \%, P<0.001)$, as were infectious complications $(12.6$ vs $5.7 \%, P<0.001)$.

\section{Risk of Blood Transfusion}

Significant variables linked with BTF $(P \leq 0.1)$, as listed in Table 1, were entered into a multivariate regression analysis. Independent risk factors of BTF for radical gastrectomy which included pre-operative anemia (hemoglobin $<100 \mathrm{~g} / \mathrm{L}$ ), combined multi-organ resection, tumor size $\geq 5 \mathrm{~cm}$, intraoperative blood loss $\geq 300 \mathrm{~mL}$, age $\geq 65$ years, and operation time $\geq 240 \min$ (all $P<0.05$ ), as shown in Table 2 .

\section{PSM Analysis}

After one-to-one PSM, 205 pairs of patients were included in further analysis. The clinicopathological features of patients after matching are listed in Table 1. All important basic, operative, and tumor-related variables were balanced between the two groups $(P>0.05)$, except for the pre-operative hemoglobin levels $(87.67 \pm 23.69$ vs $124.62 \pm 16.85 \mathrm{~g} / \mathrm{L}, P<0.001)$ and estimated intra-operative blood loss $(263 \pm 187$ vs $210 \pm$ $86 \mathrm{~mL}, P<0.001)$. Thirty-five patients $(17.1 \%)$ in the BTF group developed post-operative complications, which were significantly greater than in the non-BTF group $(10.2 \%, P=$ 0.044 ), whereas the infectious complication rates were similar in the two groups (10.7 vs $7.8 \%, P=0.307)$.

\section{Long-Term Outcomes of the Entire Cohort}

The median follow-up of the entire cohort was 33 months (range, 3-86). A total of 430 patients $(42.2 \%)$ died during the follow-up period with a median OS time of 61 months, of whom 384 deaths was related to cancer $(89.3 \%)$. The 1, 3, and 5-year OS rates in the non-BTF group were 88.4, 63.9, and $52.0 \%$, which were significantly greater than those in the BTF group $(86.8,54.5$, and $42.9 \%, P=0.025)$ (Fig. 2a). The median OS time in the BTF group was 41 months, which was significantly worse than in the non-BTF group (65 months, $P=0.025$ ).

Tumor recurrence was identified in 447 patients $(43.8 \%)$ in the entire cohort, with 113 patients (48.9\%) in the BTF group and 334 patients $(42.3 \%)$ in the non-BTF group $(P=0.076)$. The 1,3, and 5-year DFS rates in the group that did not receive BTF were $80.7,59.1$, and $47.3 \%$, which were significantly greater than in the BTF group $(78.1,50.9$, and $35.5 \%$, respectively, $P=0.034$ ) (Fig. 2b). The median DFS time in the BTF group was 40 months, which was lower than in the non-BTF group (57 months, $P=0.034$ ).

BTF was identified as a statistically significant prognostic factor for a reduction in $\operatorname{OS}(P=0.025)$ and DFS $(P=0.034)$ by univariate analysis in the entire cohort of patients. After adjusting for potential confounders by multivariate Cox regression analysis, BTF was identified as an independent predictive factor for both a decrease in OS (hazard ratio (HR) 1.435 , 95\% confidence interval (CI) 1.092-1.887, $P=0.010)$ and DFS (HR 1.402, 95\% CI 1.069-1.889, $P=0.014)$ in the entire cohort. Pre-, intra-, and postoperative BTF were not significantly linked to either DFS or OS after multivariate analysis of the entire cohort by subgroup analysis. Univariate and multivariate Cox regression analyses of DFS and OS in the entire cohort are shown in Supplementary Table 1 and Table 2.

\section{Long-Term Outcomes of the Propensity Matched Cohort}

After PSM, the 1,3, and 5-year OS rates in the non-BTF group were $85.2,59.3$, and $41.6 \%$, which were comparable with those in the BTF group $(87.5,54.9$, and $42.9 \%, P=0.850)$ (Fig. 3a). Similarly, the 1, 3, and 5-year DFS rates in the non-BTF and BTF groups were 77.0, 54.7, and $39.1 \%$ and 77.6, 51.3, and $37.6 \%$, respectively $(P=0.880)$ (Fig. 3 b). After adjusting for potential confounders by multivariate Cox regression analysis, there was no significant relationship between BTF and OS $(P=0.474)$ or DFS $(P=0.552)$ in the propensity matched group of patients. Univariate and multivariate Cox regression analyses of OS and DFS in the propensity matched cohort are shown in Tables 3 and 4, respectively.

\section{Discussion}

Although a number of studies have investigated the impact of peri-operative BTF on the oncological outcomes of GC patients after curative resection, the conclusions are contradictory and even confusing. ${ }^{10,12,14-17}$ Squires et al. ${ }^{10}$ conducted an analysis of 765 patients in seven institutions from the US Gastric Cancer Collaborative and concluded that BTF was significantly linked to a lower DFS and OS of patients with $\mathrm{GC}$, independent of adverse clinicopathological factors. Another multi-center retrospective study of 927 patients reported that BTF did not influence prognosis of those with stage I-IV GC. ${ }^{17}$ A possible explanation for the conflicting results was the inconsistency in patient inclusion criteria. 
Table 1 Clinicopathological characteristics of the entire study cohort stratified by receiving peri-operative blood transfusion or not, before and after propensity score matching $(n=1020)$

\begin{tabular}{|c|c|c|c|c|c|c|}
\hline \multirow[t]{2}{*}{ Variables } & \multicolumn{3}{|l|}{ Total cohort $(n=1020)$} & \multicolumn{3}{|c|}{ Propensity score matched cohort $(n=410)$} \\
\hline & BTF group $(n=231)$ & Non-BTF group $(n=789)$ & $P$ value & BTF group $(n=205)$ & Non-BTF group $(n=205)$ & $P$ value \\
\hline Gender (males) & $145(62.8 \%)$ & $545(69.1 \%)$ & 0.072 & $136(66.3 \%)$ & $147(71.7 \%)$ & 0.240 \\
\hline Age (years) & $56.73 \pm 11.79$ & $54.12 \pm 10.33$ & 0.001 & $55.71 \pm 11.84$ & $54.98 \pm 11.10$ & 0.516 \\
\hline Body mass index $\left(\mathrm{kg} / \mathrm{m}^{2}\right)$ & $21.20 \pm 2.82$ & $21.67 \pm 2.97$ & 0.032 & $21.27 \pm 2.82$ & $21.58 \pm 2.77$ & 0.263 \\
\hline ASA score & & & $<0.001$ & & & 0.183 \\
\hline 1 & $23(10.0 \%)$ & $102(12.9 \%)$ & & $22(10.7 \%)$ & $25(12.2 \%)$ & \\
\hline 2 & $152(65.8 \%)$ & $595(75.4 \%)$ & & $145(70.7 \%)$ & $125(61.0 \%)$ & \\
\hline 3 & $54(23.4 \%)$ & $90(11.4 \%)$ & & $37(18.0 \%)$ & $54(26.3 \%)$ & \\
\hline 4 & $1(0.4 \%)$ & $2(0.3 \%)$ & & $1(0.5 \%)$ & $1(0.5 \%)$ & \\
\hline Any comorbidities & $81(35.1 \%)$ & $225(28.5 \%)$ & 0.056 & $61(29.8 \%)$ & $73(35.6 \%)$ & 0.206 \\
\hline History of abdominal surgery & $25(10.8 \%)$ & $72(9.1 \%)$ & 0.439 & $23(11.2 \%)$ & $17(8.3 \%)$ & 0.318 \\
\hline Neo-adjuvant chemotherapy & $12(5.2 \%)$ & $42(5.3 \%)$ & 0.939 & $11(5.4 \%)$ & $7(3.4 \%)$ & 0.335 \\
\hline Pre-operative hemoglobin (g/L) & $87.81 \pm 23.48$ & $125.25 \pm 17.50$ & $<0.001$ & $87.67 \pm 23.69$ & $124.62 \pm 16.85$ & $<0.001$ \\
\hline Type of resection & & & 0.015 & & & 0.106 \\
\hline Proximal subtotal gastrectomy & $15(6.5 \%)$ & $29(3.7 \%)$ & & $12(5.9 \%)$ & $22(10.7 \%)$ & \\
\hline Distal subtotal gastrectomy & $144(62.3 \%)$ & $565(71.6 \%)$ & & $131(63.9 \%)$ & $134(65.4 \%)$ & \\
\hline Total gastrectomy & $71(30.7 \%)$ & $195(24.7 \%)$ & & $62(30.2 \%)$ & $49(23.9 \%)$ & \\
\hline Combined multi-organ resection & $39(16.9 \%)$ & $31(3.9 \%)$ & $<0.001$ & $21(10.2 \%)$ & $19(9.3 \%)$ & 0.739 \\
\hline Splenectomy & $15(6.5 \%)$ & $9(1.1 \%)$ & $<0.001$ & $7(3.4 \%)$ & $8(3.9 \%)$ & 0.793 \\
\hline Intra-operative blood loss (mL) & $274 \pm 227$ & $190 \pm 79$ & $<0.001$ & $263 \pm 187$ & $210 \pm 86$ & $<0.001$ \\
\hline Operation time $(\mathrm{min})$ & $221.04 \pm 62.02$ & $200.33 \pm 50.49$ & $<0.001$ & $218.96 \pm 63.01$ & $225.27 \pm 19.10$ & 0.224 \\
\hline Post-operative complications & & & $<0.001$ & & & 0.080 \\
\hline None & $187(81.0 \%)$ & $732(92.8 \%)$ & & $170(82.9 \%)$ & $184(89.8 \%)$ & \\
\hline Infectious complications & $29(12.6 \%)$ & $45(5.7 \%)$ & & $22(10.7 \%)$ & $16(7.8 \%)$ & \\
\hline Non-infectious complications & $15(6.5 \%)$ & $12(1.5 \%)$ & & $13(6.3 \%)$ & $5(2.4 \%)$ & \\
\hline Tumor size $(\mathrm{cm})$ & $6.17 \pm 2.71$ & $4.38 \pm 1.66$ & $<0.001$ & $5.62 \pm 2.39$ & $5.29 \pm 2.08$ & 0.113 \\
\hline Lymph node harvested & $22.60 \pm 8.10$ & $22.53 \pm 8.20$ & 0.911 & $22.93 \pm 8.48$ & $22.49 \pm 8.13$ & 0.593 \\
\hline Tumor location & & & 0.006 & & & 0.920 \\
\hline Upper & $30(13.0 \%)$ & $69(8.7 \%)$ & & $24(11.7 \%)$ & $26(12.7 \%)$ & \\
\hline Middle & $64(27.7 \%)$ & $157(19.9 \%)$ & & $55(26.8 \%)$ & $49(23.9 \%)$ & \\
\hline Lower & $126(54.5 \%)$ & $526(66.7 \%)$ & & $116(56.6 \%)$ & $120(58.5 \%)$ & \\
\hline Diffuse & $11(4.8 \%)$ & $37(4.7 \%)$ & & $10(4.9 \%)$ & $10(4.9 \%)$ & \\
\hline T stage & & & 0.494 & & & 0.638 \\
\hline $\mathrm{T} 1$ & $3(1.3 \%)$ & $13(1.6 \%)$ & & $3(1.5 \%)$ & $4(2.0 \%)$ & \\
\hline $\mathrm{T} 2$ & $16(6.9 \%)$ & $80(10.1 \%)$ & & $15(7.3 \%)$ & $22(10.7 \%)$ & \\
\hline $\mathrm{T} 3$ & $7(3.0 \%)$ & $21(2.7 \%)$ & & $6(2.9 \%)$ & $5(2.4 \%)$ & \\
\hline $\mathrm{T} 4$ & $205(88.7 \%)$ & $675(85.6 \%)$ & & $181(88.3 \%)$ & $174(84.9 \%)$ & \\
\hline $\mathrm{N}$ stage & & & 0.615 & & & 0.543 \\
\hline No & $46(19.9 \%)$ & $167(21.2 \%)$ & & $40(19.5 \%)$ & $32(15.6 \%)$ & \\
\hline N1 & $41(17.7 \%)$ & $165(20.9 \%)$ & & $37(18.0 \%)$ & $32(15.6 \%)$ & \\
\hline $\mathrm{N} 2$ & $62(26.8 \%)$ & $206(26.1 \%)$ & & $55(27.1 \%)$ & $65(31.7 \%)$ & \\
\hline N3 & $82(35.5 \%)$ & $251(31.8 \%)$ & & $73(35.6 \%)$ & $76(37.1 \%)$ & \\
\hline pTNM stage* & & & 0.180 & & & 0.539 \\
\hline IIA & $10(4.3 \%)$ & $58(7.4 \%)$ & & $10(4.9 \%)$ & $12(5.9 \%)$ & \\
\hline IIB & $44(19.0 \%)$ & $171(21.7 \%)$ & & $39(19.0 \%)$ & $35(17.1 \%)$ & \\
\hline IIIA & $36(15.6 \%)$ & $128(16.2 \%)$ & & $32(15.6 \%)$ & $28(13.7 \%)$ & \\
\hline IIIB & $50(21.6 \%)$ & $181(22.9 \%)$ & & $41(20.0 \%)$ & $55(26.8 \%)$ & \\
\hline IIIC & $91(39.4 \%)$ & $251(31.8 \%)$ & & $83(40.5 \%)$ & $75(36.6 \%)$ & \\
\hline Adjuvant chemotherapy ${ }^{\mathrm{b}}$ & $180, \mathrm{a}(77.9 \%)$ & $580, \mathrm{~b}(73.5 \%)$ & 0.176 & $157, \mathrm{c}(76.6 \%)$ & $150, \mathrm{~d}(73.2 \%)$ & 0.425 \\
\hline
\end{tabular}

Data are presented as mean $\pm \mathrm{SD}$ or $n(\%)$

$B T F$ blood transfusion, ASA American Society of Anesthesiologist

*Tumor stages are based on the seventh edition of the Union for International Cancer Control TNM classification

${ }^{\mathrm{b}}$ Including a few patients received adjuvant concurrent chemoradiotherapy: 7 patients in group a, 26 patients in group b, 6 patients in group c, and 7 patients in group $\mathrm{d}$

Thus, it seems difficult to determine the effects of BTF on the long-term survival rates of patients having stage I GC, who experience very low rates of receiving BTF but have significantly longer long-term survival times. ${ }^{10,14,16,17}$ Even patients with stage IV GC, who experienced extremely disappointing survival times, are included in a number of the previous studies. ${ }^{17}$ Kanda et al. ${ }^{12}$ investigated the prognostic influence of BTF on patients with stage II/III GC, but included only 250 
Table 2 Multivariate analysis of possible predictors for perioperative blood transfusion (BTF)

\begin{tabular}{lccr}
\hline Variables & Odds ratio (OR) & $95 \%$ Confidence interval (CI) & $P$ value \\
\hline Pre-operative hemoglobin $<100 \mathrm{~g} / \mathrm{L}$ & 43.609 & $27.466-69.242$ & $<0.001$ \\
Combined multi-organ resection & 3.877 & $1.931-7.786$ & $<0.001$ \\
Tumor size $\geq 5 \mathrm{~cm}$ & 2.558 & $1.543-4.240$ & $<0.001$ \\
Intra-operative blood loss $\geq 300 \mathrm{~mL}$ & 2.052 & $1.205-3.494$ & 0.008 \\
Age $\geq 65$ years & 1.660 & $1.019-2.706$ & 0.042 \\
Operation time $\geq 240$ min & 1.640 & $1.010-2.664$ & 0.045 \\
\hline
\end{tabular}

patients, 57 who underwent BTF. Another issue to be considered is that most of the previous studies mainly included patients before the year 2010 and even before 2000, with a long study time period over 10 years. Remarkable advances in surgical techniques, peri-operative care, and adjuvant treatments for GC, over time, have resulted in obvious heterogeneity, which might have biased the results and conclusions.

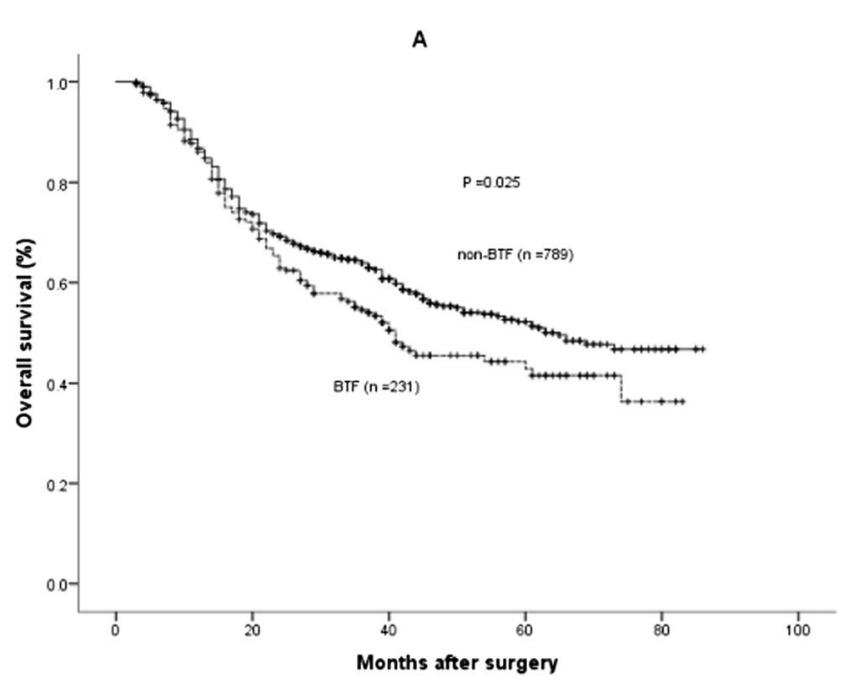

B

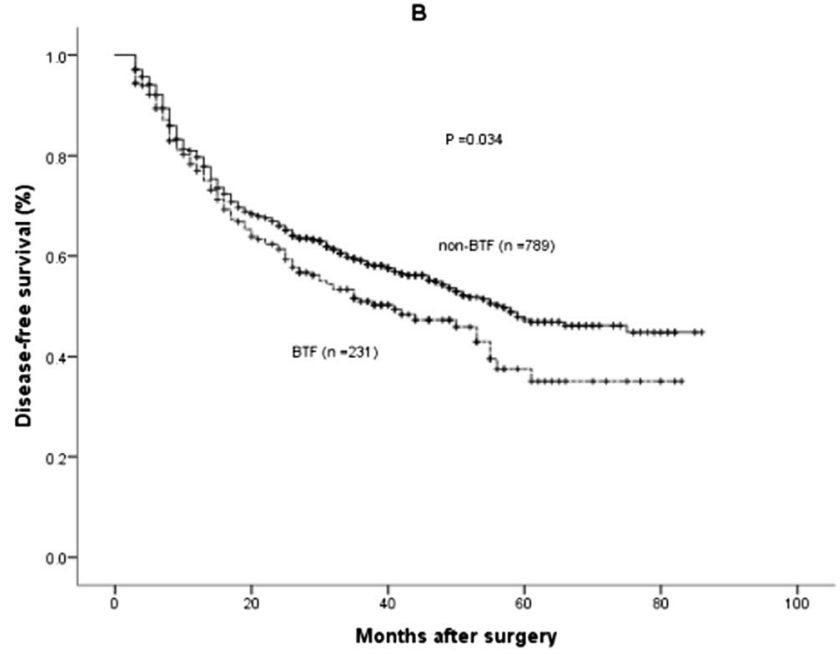

Fig. 2 Survival cures of the peri-operative blood transfusion (BTF) and non-BTF groups in the entire cohort. a Overall survival $(P=0.025$ by log-rank test). b Disease-free survival $(P=0.034$ by log-rank test $)$
As listed in Table 1 in the present study and in previous studies, the clinical and pathological characteristics between BTF and non-BTF patients were significantly different before matching. Some of these factors, such as tumor size, tumor location, and combined multi-organ resection, are well-known adverse predictors for OS and DFS after gastrectomy for GC. Meanwhile, some of these factors were also independent risk
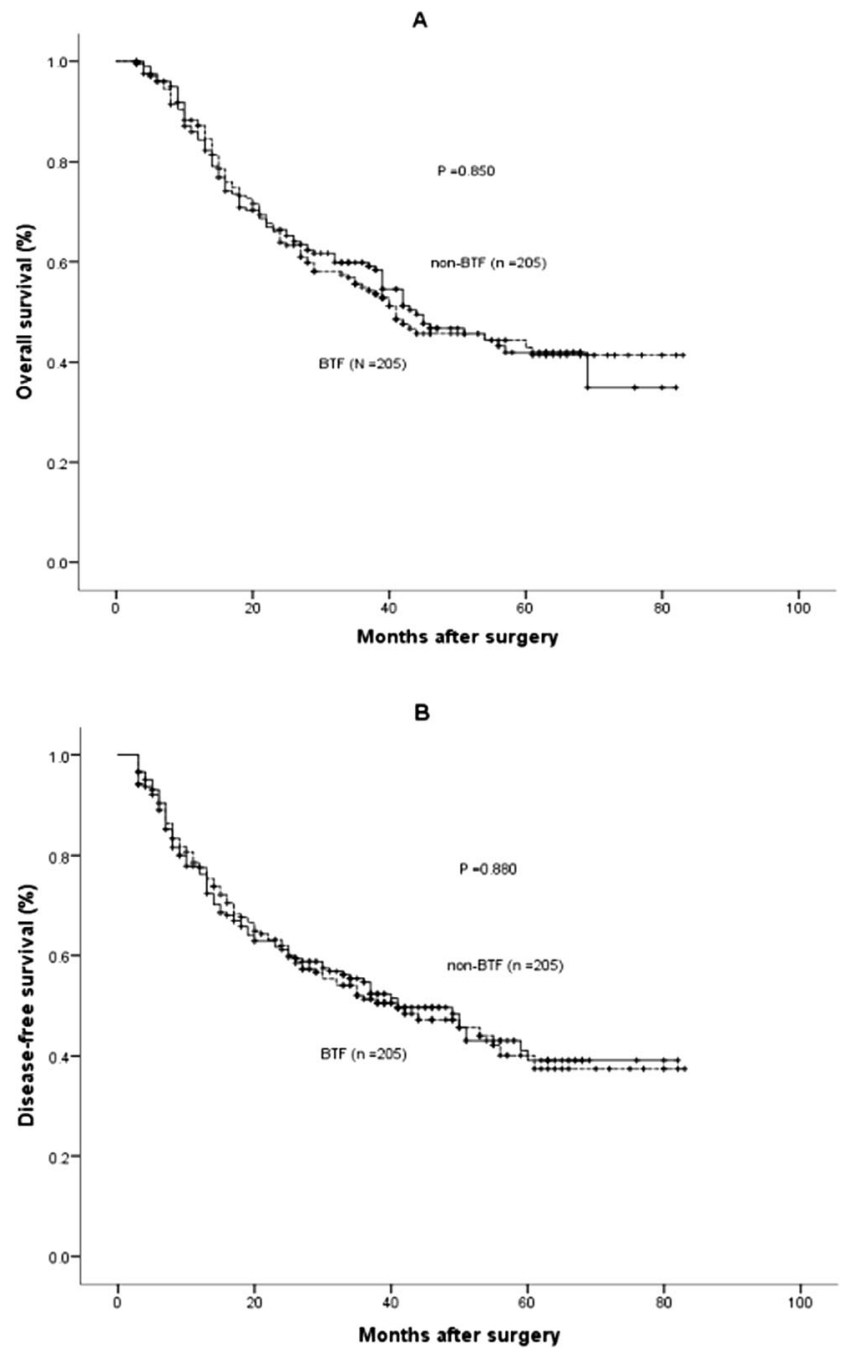

Fig. 3 Survival cures of the peri-operative blood transfusion (BTF) and non-BTF groups in the propensity score matched cohort. a Overall survival $(P=0.850$ by log-rank test). b Disease-free survival $(P=0.880$ by log-rank test) 
Table 3 Univariate and multivariate analyses of prognostic factors for overall survival after radical resection of stage II/III gastric cancer in the propensity matched cohort $(n=$ 410)

\begin{tabular}{|c|c|c|c|c|c|}
\hline Variables & $N$ & $\begin{array}{l}\text { Median OS } \pm \mathrm{SD} \\
\text { (months) }\end{array}$ & $\begin{array}{l}\text { UV } \\
P \text { value }\end{array}$ & $\begin{array}{l}\text { MV } \\
\text { HR }(95 \% \text { CI })\end{array}$ & $\begin{array}{l}\mathrm{MV} \\
P \text { value }\end{array}$ \\
\hline \multicolumn{6}{|l|}{ Gender } \\
\hline Male & 283 & $43.0 \pm 4.6$ & 0.153 & & \\
\hline Female & 127 & $41.0 \pm 7.6$ & & & \\
\hline \multicolumn{6}{|l|}{ Age (years) } \\
\hline$\geq 65$ & 99 & $42.0 \pm 6.0$ & 0.317 & & \\
\hline$<65$ & 311 & $42.0 \pm 4.8$ & & & \\
\hline \multicolumn{6}{|l|}{ BMI $\left(\mathrm{kg} / \mathrm{m}^{2}\right)$} \\
\hline$\geq 25$ & 47 & $56.0 \pm 5.0$ & 0.322 & & \\
\hline$<25$ & 363 & $42.0 \pm 3.7$ & & & \\
\hline \multicolumn{6}{|l|}{ ASA score } \\
\hline$\geq 3$ & 93 & $42.0 \pm 5.2$ & 0.776 & & \\
\hline$<3$ & 317 & $43.0 \pm 4.8$ & & & \\
\hline \multicolumn{6}{|l|}{ Comorbidities } \\
\hline Yes & 134 & $42.0 \pm 5.5$ & 0.781 & & \\
\hline No & 276 & $43.0 \pm 5.5$ & & & \\
\hline \multicolumn{6}{|l|}{ Pre-operative hemoglobin } \\
\hline$\geq 100$ & 244 & $43.0 \pm 4.6$ & 0.976 & & \\
\hline$<100$ & 166 & $41.0 \pm 7.6$ & & & \\
\hline \multicolumn{6}{|l|}{ Neoadjuvant chemotherapy } \\
\hline Yes & 18 & $60.0 \pm 15.1$ & 0.751 & & \\
\hline No & 392 & $42.0 \pm 3.9$ & & & \\
\hline \multicolumn{6}{|l|}{ Type of resection } \\
\hline Total gastrectomy & 111 & $42.0 \pm 10.6$ & 0.818 & & \\
\hline Sub-total gastrectomy & 299 & $42.0 \pm 3.8$ & & & \\
\hline \multicolumn{6}{|l|}{ Combined multi-organ resection } \\
\hline Yes & 40 & $29.0 \pm 8.2$ & 0.257 & & \\
\hline No & 370 & $43.0 \pm 3.8$ & & & \\
\hline \multicolumn{6}{|l|}{ Splenectomy } \\
\hline Yes & 15 & $29.0 \pm 6.5$ & 0.703 & & \\
\hline No & 395 & $42.0 \pm 3.8$ & & & \\
\hline \multicolumn{6}{|l|}{ Operation time } \\
\hline$\geq 240 \mathrm{~min}$ & 136 & $39.0 \pm 2.8$ & 0.035 & $1.375(1.029-1.837)$ & 0.031 \\
\hline$<240 \min$ & 274 & $51.0 \pm 2.2$ & & & \\
\hline \multicolumn{6}{|l|}{ Intra-operative blood loss } \\
\hline$\geq 300 \mathrm{~mL}$ & 137 & $29.0 \pm 5.0$ & 0.001 & & 0.094 \\
\hline$<300 \mathrm{~mL}$ & 273 & $54.0 \pm 2.1$ & & & \\
\hline \multicolumn{6}{|l|}{ Tumor location } \\
\hline Lower third & 236 & $42.0 \pm 4.7$ & 0.631 & & \\
\hline Upper, middle third or diffused & 174 & $44.0 \pm 7.7$ & & & \\
\hline \multicolumn{6}{|l|}{ Tumor size } \\
\hline$\geq 5 \mathrm{~cm}$ & 268 & $39.0 \pm 3.6$ & 0.116 & & \\
\hline$<5 \mathrm{~cm}$ & 142 & $54.0 \pm 4.5$ & & & \\
\hline \multicolumn{6}{|l|}{ Depth of invasion ${ }^{\mathrm{a}}$} \\
\hline $\mathrm{T} 4$ & 355 & $39.0 \pm 3.0$ & 0.001 & & 0.380 \\
\hline $\mathrm{T} 1-\mathrm{T} 3$ & 55 & Undefined $^{\mathrm{b}}$ & & & \\
\hline \multicolumn{6}{|l|}{ Lymph node metastasis } \\
\hline Yes & 338 & $39.0 \pm 3.5$ & $<0.001$ & & 0.802 \\
\hline No & 72 & Undefined $^{\mathrm{b}}$ & & & \\
\hline
\end{tabular}


Table 3 (continued)

\begin{tabular}{|c|c|c|c|c|c|}
\hline Variables & $N$ & $\begin{array}{l}\text { Median OS } \pm \mathrm{SD} \\
\text { (months) }\end{array}$ & $\begin{array}{l}\text { UV } \\
P \text { value }\end{array}$ & $\begin{array}{l}\text { MV } \\
\text { HR }(95 \% \text { CI })\end{array}$ & $\begin{array}{l}\mathrm{MV} \\
P \text { value }\end{array}$ \\
\hline \multicolumn{6}{|c|}{ pTNM stage $^{a}$} \\
\hline III & 316 & $35.0 \pm 3.5$ & \multirow[t]{2}{*}{$<0.001$} & \multirow[t]{2}{*}{$3.222(2.044-5.077)$} & \multirow[t]{2}{*}{$<0.001$} \\
\hline II & 94 & Undefined $^{\mathrm{b}}$ & & & \\
\hline \multicolumn{6}{|c|}{ Peri-operative blood transfusion } \\
\hline Yes & 205 & $42.0 \pm 6.6$ & \multirow[t]{2}{*}{0.850} & & \multirow[t]{2}{*}{0.474} \\
\hline No & 205 & $44.0 \pm 4.6$ & & & \\
\hline \multicolumn{6}{|c|}{ Pre-operative blood transfusion } \\
\hline Yes & 95 & $41.0 \pm 4.2$ & \multirow[t]{2}{*}{0.957} & & \\
\hline No & 315 & $44.0 \pm 4.4$ & & & \\
\hline \multicolumn{6}{|c|}{ Intra-operative blood transfusion } \\
\hline Yes & 84 & $36.0 \pm 2.6$ & \multirow[t]{2}{*}{0.479} & & \\
\hline No & 326 & $43.0 \pm 3.7$ & & & \\
\hline \multicolumn{6}{|c|}{ Post-operative blood transfusion } \\
\hline Yes & 42 & $37.0 \pm 11.0$ & \multirow[t]{2}{*}{0.071} & & \multirow[t]{2}{*}{0.151} \\
\hline No & 368 & $44.0 \pm 4.3$ & & & \\
\hline \multicolumn{6}{|c|}{ Adjuvant chemotherapy } \\
\hline Yes & 307 & $42.0 \pm 4.6$ & \multirow[t]{2}{*}{0.479} & & \\
\hline No & 103 & $43.0 \pm 3.5$ & & & \\
\hline
\end{tabular}

$B M I$ body mass index, $A S A$ American Society of Anesthesiologist, $O S$ overall survival, $S D$ standard deviation, $C I$ confidence interval, $H R$ hazard ratio, $U V$ univariate analysis, $M V$ multivariate analysis

${ }^{a}$ Tumor stages are based on the seventh edition of the Union for International Cancer Control TNM classification

${ }^{\mathrm{b}}$ The specific median overall survival time is too long to be determined in this subgroup during the follow-up

for peri-operative BTF, as listed in Table 2. Thus, the association between BTF and decreased long-term survival may be befuddled by other variables. Therefore, as the first study to our knowledge, we have investigated the putative impact of peri-operative BTF on the prognosis of patients who underwent radical gastrectomy with pathologically diagnosed stage II/III GC. We used PSM and multivariate Cox regression analysis to balance out differences in clinicopathological characteristics between BTF and non-BTF patients and to explore the influence of other potential risk factors. Our study verified that the influence of tumor- and operation-associated factors including advanced tumor stage and longer duration of surgery was significantly more important than the influence of BTF on oncological outcomes.

BTF was clearly shown to be linked to both a decrease in OS and DFS after univariate and multivariate analyses in the entire cohort before matching. However, because of the significant differences in prognostic factors between BTF and non-BTF patients, this conclusion should be carefully interpreted, and as shown in the present study may well be coincidental. PSM analysis is widely used in retrospective cohort studies to control for confounding biases, mimicking a randomized trial, with the assumption that all related confounders are controlled. ${ }^{21}$ As listed in Table 1, after matching, most of the important basic characteristics become comparable except for preoperative hemoglobin levels and intra-operative blood loss, which were considered to be the main factors associated with BTF. These 2 factors were not used for enrolment for matching to avoid too many patients who received BTF being excluded because of a lack of matching. Further multivariate analysis identified that either pre-operative anemia $(<$ hemoglobin $100 \mathrm{~g} / \mathrm{L}$ ) or intra-operative blood loss $\geq 300 \mathrm{~mL}$ were independent risk factor for poorer OS or DFS in the propensity matched cohort.

BTF was no longer significantly associated with poorer OS $(P=0.850)$ or DFS $(P=0.974)$ on univariate analysis in the propensity matched cohort. To adjust further for other misleading factors, multivariate Cox regression analyses with possible predictors $(P \leq 0.1$ in the univariate analysis) were applied, and BTF was confirmed not to be an independent risk factor for DFS or OS $(P=0.552, P=0.474$, respectively). Therefore, the combined use of PSM and multivariate Cox regression analyses can offer statistical power to improve the reliability of our final conclusions. Thus, the negative association between BTF and long-term outcomes in the entire cohort is likely not associated with BTF itself but rather with the clinical circumstance requiring blood transfusions.

The same conflicting conclusions were drawn for hepatocellular carcinoma, ${ }^{22}$ rectal cancer ${ }^{24}$ prostate cancer, ${ }^{25}$ and 
Table 4 Univariate and multivariate analyses of prognostic factors for disease-free survival after radical resection of stage II/III gastric cancer in the propensity matched cohort $(n=410)$

\begin{tabular}{|c|c|c|c|c|c|}
\hline Variables & $N$ & Median OS \pm SD (months) & $\begin{array}{l}\mathrm{UV} \\
P \text { value }\end{array}$ & $\begin{array}{l}\text { MV } \\
\text { HR (95\% CI) }\end{array}$ & $\begin{array}{l}\mathrm{MV} \\
P \text { value }\end{array}$ \\
\hline \multicolumn{6}{|l|}{ Gender } \\
\hline Male & 283 & $41.0 \pm 5.3$ & 0.925 & & \\
\hline Female & 127 & $41.0 \pm 8.4$ & & & \\
\hline \multicolumn{6}{|l|}{ Age (years) } \\
\hline$\geq 65$ & 99 & $41.0 \pm 4.9$ & 0.912 & & \\
\hline$<65$ & 311 & $41.0 \pm 3.2$ & & & \\
\hline \multicolumn{6}{|l|}{ BMI $\left(\mathrm{kg} / \mathrm{m}^{2}\right)$} \\
\hline$\geq 25$ & 47 & $50.0 \pm 13.8$ & 0.382 & & \\
\hline$<25$ & 363 & $41.0 \pm 5.1$ & & & \\
\hline \multicolumn{6}{|l|}{ ASA score } \\
\hline$\geq 3$ & 93 & $37.0 \pm 7.6$ & 0.634 & & \\
\hline$<3$ & 317 & $42.0 \pm 6.4$ & & & \\
\hline \multicolumn{6}{|l|}{ Comorbidities } \\
\hline Yes & 134 & $37.0 \pm 6.1$ & 0.530 & & \\
\hline No & 276 & $42.0 \pm 4.6$ & & & \\
\hline \multicolumn{6}{|l|}{ Pre-operative hemoglobin } \\
\hline$\geq 100$ & 244 & $42.0 \pm 7.3$ & 0.909 & & \\
\hline$<100$ & 166 & $41.0 \pm 5.8$ & & & \\
\hline \multicolumn{6}{|l|}{ Neoadjuvant chemotherapy } \\
\hline Yes & 18 & $42.0 \pm 14.6$ & 0.673 & & \\
\hline No & 392 & $41.0 \pm 4.9$ & & & \\
\hline \multicolumn{6}{|l|}{ Type of resection } \\
\hline Total gastrectomy & 111 & $40.0 \pm 6.6$ & 0.961 & & \\
\hline Sub-total gastrectomy & 299 & $41.0 \pm 4.9$ & & & \\
\hline \multicolumn{6}{|l|}{ Combined multi-organ resection } \\
\hline Yes & 40 & $26.0 \pm 15.8$ & 0.290 & & \\
\hline No & 370 & $41.0 \pm 5.5$ & & & \\
\hline \multicolumn{6}{|l|}{ Splenectomy } \\
\hline Yes & 15 & $23.0 \pm 4.6$ & 0.473 & & \\
\hline No & 395 & $41.0 \pm 4.3$ & & & \\
\hline \multicolumn{6}{|l|}{ Operation time } \\
\hline$\geq 240 \mathrm{~min}$ & 136 & $27.0 \pm 5.4$ & 0.010 & $1.452(1.089-1.935)$ & 0.011 \\
\hline$<240 \min$ & 274 & $50.0 \pm 7.6$ & & & \\
\hline \multicolumn{6}{|l|}{ Intra-operative blood loss } \\
\hline$\geq 300 \mathrm{~mL}$ & 137 & $25.0 \pm 3.6$ & $<0.001$ & & 0.059 \\
\hline$<300 \mathrm{~mL}$ & 273 & $51.0 \pm 2.7$ & & & \\
\hline \multicolumn{6}{|l|}{ Tumor location } \\
\hline Lower third & 236 & $41.0 \pm 5.1$ & 0.798 & & \\
\hline Upper, middle third or diffused & 174 & $40.0 \pm 8.4$ & & & \\
\hline \multicolumn{6}{|l|}{ Tumor size } \\
\hline$\geq 5 \mathrm{~cm}$ & 268 & $36.0 \pm 6.7$ & 0.135 & & \\
\hline$<5 \mathrm{~cm}$ & 142 & $51.0 \pm 8.8$ & & & \\
\hline \multicolumn{6}{|l|}{ Depth of invasion ${ }^{\mathrm{a}}$} \\
\hline $\mathrm{T} 4$ & 355 & $36.0 \pm 5.0$ & 0.001 & & 0.466 \\
\hline $\mathrm{T} 1-\mathrm{T} 3$ & 55 & Undefined $^{\mathrm{b}}$ & & & \\
\hline \multicolumn{6}{|l|}{ Lymph node metastasis } \\
\hline Yes & 338 & $35.0 \pm 4.2$ & $<0.001$ & & 0.958 \\
\hline
\end{tabular}


Table 4 (continued)

\begin{tabular}{|c|c|c|c|c|c|}
\hline Variables & $N$ & Median OS \pm SD (months) & $\begin{array}{l}\mathrm{UV} \\
P \text { value }\end{array}$ & $\begin{array}{l}\text { MV } \\
\text { HR }(95 \% \mathrm{CI})\end{array}$ & $\begin{array}{l}\text { MV } \\
P \text { value }\end{array}$ \\
\hline No & 72 & Undefined $^{\mathrm{b}}$ & & & \\
\hline \multicolumn{6}{|c|}{ pTNM stage $^{a}$} \\
\hline III & 316 & $30.0 \pm 3.6$ & $<0.001$ & $3.343(2.122-5.268)$ & $<0.001$ \\
\hline II & 94 & Undefined $^{\mathrm{b}}$ & & & \\
\hline \multicolumn{6}{|c|}{ Peri-operative blood transfusion } \\
\hline Yes & 205 & $41.0 \pm 7.9$ & 0.880 & & 0.552 \\
\hline No & 205 & $41.0 \pm 5.4$ & & & \\
\hline \multicolumn{6}{|c|}{ Pre-operative blood transfusion } \\
\hline Yes & 95 & $41.0 \pm 4.2$ & 0.957 & & \\
\hline No & 315 & $42.0 \pm 4.4$ & & & \\
\hline \multicolumn{6}{|c|}{ Intra-operative blood transfusion } \\
\hline Yes & 84 & $29.0 \pm 4.5$ & 0.439 & & \\
\hline No & 326 & $41.0 \pm 13.7$ & & & \\
\hline \multicolumn{6}{|c|}{ Post-operative blood transfusion } \\
\hline Yes & 42 & $25.0 \pm 10.9$ & 0.073 & & 0.157 \\
\hline No & 368 & $44.0 \pm 5.1$ & & & \\
\hline \multicolumn{6}{|c|}{ Adjuvant chemotherapy } \\
\hline Yes & 307 & $41.0 \pm 6.7$ & 0.589 & & \\
\hline No & 103 & $41.0 \pm 6.7$ & & & \\
\hline
\end{tabular}

$B M I$ body mass index, $A S A$ American Society of Anesthesiologist, $O S$ overall survival, $S D$ standard deviation, $C I$ confidence interval, $H R$ hazard ratio, $U V$ univariate analysis, $M V$ multivariate analysis

${ }^{\mathrm{a}}$ Tumor stages are based on the seventh edition of the Union for International Cancer Control TNM classification

${ }^{\mathrm{b}}$ The specific median disease-free survival time is too long to be determined in this subgroup during the follow-up

cholangiocarcinoma. ${ }^{26}$ BTF was confirmed not to be significantly associated with oncological outcomes by PSM analysis. The finding of these studies, that BTF is a surrogate marker for higher risk patients and does not influence long-term survival, could be theoretically confirmed by a randomized controlled trial. Whereas, a large sample-based observational analysis appears to be the best alternative to investigate the effects of BTF on oncological survival. PSM analysis provides researchers with the ability to balance all potential risk factors between two groups, thus mimicking a randomized controlled trial. ${ }^{27}$

Even though BTF was not identified to influence long-term survival in the present study, avoiding unnecessary BTF is of prime importance for a number of reasons. Excepting cost, the possible adverse effects of BTF are well known, such as immunomodulation, transfusion-transmitted diseases, and a higher risk of peri-operative morbidity and mortality. ${ }^{28,29}$ Various studies have revealed that a restrictive (hemoglobin level 70 or $80 \mathrm{~g} / \mathrm{L}$ ) red cell transfusion strategy was noninferior to a liberal strategy in cardiac and hip surgical patients with respect to peri-operative morbidity and mortality. ${ }^{30-32}$ But whether the results would be the same in patients who underwent gastrectomy has not been investigated, and there is also a lack of research on whether different BTF strategies have an impact on long-term survival.

It is worth pointing out that only stage III and longer operation time ( $\geq 240 \mathrm{~min}$ ) were confirmed as independent risk factors for both decreased OS and DFS after radical gastrectomy for stage II/III GC. Whereas quite a few of well-known factors which significantly affect oncological outcomes of GC, such as depth of invasion, lymph node metastasis, and adjuvant chemotherapy, were not identified to be independently associated with long-term outcomes in the propensity score matched cohort. ${ }^{33,34}$ The possible explanation is that pTNM stage, which combines the depth of tumor invasion and lymph node metastasis, is identified as the most powerful indicator for predicting the prognosis. If we do not enroll pTNM stage into multivariable Cox regression, both of the depth of tumor invasion and lymph node metastasis were identified to be significantly associated with the prognosis (HR 2.309, 95\% CI 1.356-3.931, $P=0.002$; HR $2.343,95 \%$ CI $1.436-3.824, P=0.001$ ). The reason for adjuvant chemotherapy is that patients with stage II GC seem less likely to receive adjuvant chemotherapy than those with stage III diseases, although the difference was not significant ( 29.8 vs $23.7 \%, P=0.235$ ). 
Thus, adjuvant chemotherapy seems a confounding factor in the association between tumor stage and prognosis, rather than an independent risk factor for prognosis in the present study. A longer operation time usually means that the operation is technically difficult, probably due to overweight, iatrogenic injury, extended lymphadenectomy, or combined multi-organ resection, which may affect the long-term survivals. But the results may change if the cutoff value of operation time was changed. Thus, the conclusion must be interpreted with caution. Additionally, due to insufficient data on immune functions and all of the transfused patients in the present study were performed nonirradiated packed red blood cells, whether the results were the same among patients who received irradiated red blood cells or whole blood needed further investigation.

Finally, although there have been several studies investigating the association between peri-operative BTF and the prognosis of patients who underwent gastrectomy for GC, the definition of peri-operative BTF and BTF protocol varied significantly among different studies. There was one study that included only patients who received BTF intra- and/or post-operatively, ${ }^{10}$ while the majority of the previous studies included patients who received BTF 1 or 2 weeks before surgery, and 1 or 2 weeks, even 1 month after surgery. ${ }^{12,14-16}$ While in the present study, peri-operative BTF was defined as the transfusion of packed erythrocytes from the admission time to the day of discharge during hospitalization (usually 35 days before operation and 10-14 days thereafter). Although the exact time span is not fixed as previous studies, the BTF records during the present hospitalization is easy to get, accurate, and reliable. Given the varied definitions of perioperative BTF and BTF protocols among different hospitals and doctors, the conclusions must be cited with caution, and an international multi-center study with larger sample size is necessary in the future.

There are several limitations of the present study including its retrospective nature and single-institution design. Second, the median follow-up time (33 months) was relatively short and the median OS and DFS in several subgroups could not be determined. Third, the pre-operative hemoglobin and intraoperative blood loss were unbalanced between the patients who were given BTF and those who were not in the propensity score matched cohort, which may affect the reliability of our conclusions. Fourth, although propensity score matching analysis has the advantage of reducing selective bias, it restricts the analysis to a relatively small proportion of the patients, thus dramatically increases the possibility of a type II error, limits the statistical power, and inflates the confidence intervals. Last but not the least, some patients in the present study received platelet or plasma transfusions, which might also affect the patients' immune status or interact with BTF to influence the oncological outcomes; ${ }^{35,36}$ we did not investigate these potential associations.

\section{Conclusions}

The present study from a high-volume center in China has revealed that $\mathrm{BTF}$ is not significantly linked with $\mathrm{OS}$ and DFS for stage II/III GC after radical gastrectomy, by a combination of PSM and multivariate Cox regression analyses. Worse oncological outcomes are caused by the clinical circumstances requiring BTF, including a longer operation time and advanced tumor stage, and are not due to BTF per se.

Author Contributions Hua Xiao, Wu Liu, and Yongzhong Ouyang designed the study. Hua Xiao, Wu Liu, and Hu Quan collected and analyzed data. Hua Xiao and Wu Liu wrote the paper. Yongzhong Ouyang revised the paper. Hua Xiao and Wu Liu are co-first authors and contribute equally to this work.

Funding This study was funded by the 2017 Annual Research Project of Health and Family Planning Commission of Hunan Province (No. B2017101).

\section{Compliance with Ethical Standards}

Conflict of Interest The authors declare that they have no conflict of interest.

Ethical Approval All procedures performed in studies involving human participants were in accordance with the ethical standards of the institutional and/or national research committee and with the 1964 Helsinki declaration and its later amendments or comparable ethical standards. This article does not contain any studies with animal subjects performed by any of the authors.

Open Access This article is distributed under the terms of the Creative Commons Attribution 4.0 International License (http:// creativecommons.org/licenses/by/4.0/), which permits unrestricted use, distribution, and reproduction in any medium, provided you give appropriate credit to the original author(s) and the source, provide a link to the Creative Commons license, and indicate if changes were made.

\section{References}

1. Torre LA, Bray F, Siegel RL, Ferlay J, Lorlet-Tieulent J, Jemal A. Global cancer statistics, 2012. CA Cancer J Clin. 2015; 65:87-108.

2. Chen W, Zheng R, Baade PD, Zhang S, Zeng H, Bray F, et al. Cancer statistics in China, 2015. CA Cancer J Clin. 2016; 66: 115-32.

3. Japanese Gastric Cancer Association. Japanese gastric cancer treatment guidelines 2014 (ver. 4). Gastric Cancer. 2017; 20:1-19.

4. Ajani JA, D'Amico TA, Almhanna K, Bentrem DJ, Chao J, Das P, et al. Gastric cancer, Version 3.2016, NCCN Clinical Practice Guidelines in Oncology. J Natl Compr Canc Netw. 2016; 14: 1286-312.

5. Smyth EC, Verheij M, Allum W, Cunningham D, Cervantes A, Arnold D; ESMO Guidelines Committee. Gastric cancer: ESMO Clinical Practice Guidelines for diagnosis, treatment and follow-up. Ann Oncol. 2016; 27:v38-v49.

6. Shen JG, Cheong JH, Hyung WJ, Kim J, Choi SH, Noh SH. Pretreatment anemia is associated with poorer survival in patients with stage I and II gastric cancer. J Surg Oncol. 2015; 91:126-30. 
7. Sasako M, Sano T, Yamamoto S, Kurokawa Y, Nashimoto A, Kurita A, et al. D2 lymphadenectomy alone or with para-aortic nodal dissection for gastric cancer. N Engl J Med. 2008; 359: 453-62.

8. Ecker BL, Simmons KD, Zaheer S, Poe SL, Bartlett EK, Drebin JA, et al. Blood transfusion in major abdominal surgery for malignant tumors: a trend analysis using the national surgical quality improvement program. JAMA Surg. 2016; 151:518-25.

9. Sun C, Wang Y, Yao HS, Hu ZQ. Allogeneic blood transfusion and the prognosis of gastric cancer patients: systematic review and meta-analysis. Int J Surg. 2015; 13:102-10.

10. Squires MH 3rd, Kooby DA, Poultsides GA, Weber SM, Bloomston M, Fields RC, et al. Effect of perioperative transfusion on recurrence and survival after gastric cancer resection: a 7institution analysis of 765 patients from the US Gastric Cancer Collaborative. J Am Coll Surg. 2015; 211:767-77.

11. Li L, Zhu D, Chen X, Huang Y, Ouyang M, Zhang W. Perioperative allogenenic blood transfusion is associated with worse clinical outcome for patients undergoing gastric carcinoma surgery: a metaanalysis. Medicine (Baltimore). 2015; 94:e1574.

12. Kanda M, Kobayashi D, Tanaka C, Iwata N, Yamada S, Fujii T, et al. Adverse prognostic impact of perioperative allogeneic transfusion on patients with stage II/III gastric cancer. Gastric Cancer. 2016; 19:255-63.

13. Aquina CT, Blumberg N, Becerra AZ, Boscoe FP, Schymura MJ, Noyes K, et al. Association among blood transfusion, sepsis, and decreased long-term survival after colon cancer resection. Ann Surg. 2017; 266:311-17.

14. Pacelli F, Rosa F, Marrelli D, Pedrazzani C, Bossola M, Marchet A, et al. Do perioperative blood transfusions influence prognosis of gastric cancer patients? Analysis of 927 patients and interactions with splenectomy. Ann Surg Oncol. 2011; 18:1615-23.

15. Rausei S, Ruspi L, Galli F, Tirotta F, Inversini D, Frattini F, et al. Peri-operative blood transfusion in gastric cancer surgery: prognostic or confounding factor? Int J Surg. 2013; 11:S100-3.

16. Zhou HY, Yi W, Wang J, Zhang J, Wang WJ, Hu ZQ. Association of perioperative allogeneic blood transfusions and prognosis of patients with gastric cancer after curative gastrectomy. Am J Surg. 2014; 208:80-7.

17. Cui J, Deng J, Ding X, Zhang L, Zhang R, Wu W, et al. Blood transfusion does not affect survival of gastric cancer patients. J Surg Res. 2016; 200:98-104.

18. Xiao H, Ma M, Xiao Y, Ouyang Y, Tang M, Zhou K, et al. Incomplete resection and linitis plastica are factors for poor survival after extended multiorgan resection in gastric cancer patients. Sci Rep. 2017; 7:15800.

19. Xiao H, Xiao Y, Quan H, Liu W, Pan S, Ouyang Y. Intra-abdominal infection after radical gastrectomy for gastric cancer: incidence, pathogens, risk factors and outcomes. Int J Surg. 2017; 48:195-200.

20. Kwon SJ. Evaluation of the 7th UICC TNM Staging System of Gastric Cancer. J Gastric Cancer. 2011; 11:78-85.

21. Rubin DB, Thomas N. Matching using estimated propensity scores: relating theory to practice. Biometrics. 1996; 52:249-64.

22. Yang T, Lu JH, Lau WY, Zhang TY, Zhang H, Shen YN, et al. Perioperative blood transfusion does not influence recurrence-free and overall survival after curative resection for hepatocellular carcinoma: a propensity score matching analysis. J Hepatol. 2016; 64:583-93.

23. Dindo D, Demartines N, Clavien PA. Classification of surgical complications: a new proposal with evaluation in a cohort of 6336 patients and results of a survey. Ann Surg. 2004; 240:205-13.

24. Warschkow R, Güller U, Köberle D, Müller SA, Steffen T, Thurnheer M, et al. Perioperative blood transfusions do not impact overall and disease-free survival after curative rectal cancer resection: a propensity score analysis. Ann Surg. 2014; 259:131-38.

25. Boehm K, Beyer B, Tennstedt P, Schiffmann J, Budaeus L, Haese A, et al. No impact of blood transfusion on oncological outcome after radical prostatectomy in patients with prostate cancer. World J Urol. 2014; 33:801-6.

26. Muller SA, Mehrabi A, Rahbari NN, Warschkow R, Elbers H, Leowardi $\mathrm{C}$, et al. Allogeneic blood transfusion does not affect outcome after curative resection for advanced cholangiocarcinoma. Ann Surg Oncol. 2014; 21:155-64.

27. Lonjon G, Boutron I, Trinquart L, Ahmad N, Aim F, Nizard R, et al. Comparison of treatment effect estimates from prospective nonrandomized studies with propensity score analysis and randomized controlled trials of surgical procedures. Ann Surg. 2014; 259: $18-25$.

28. Carson JL, Triulzi DJ, Ness PM. Indication for and adverse effects of red-cell transfusion. N Eng J Med. 2017; 377:1261-72.

29. Elmi M, Mahar A, Kagedan D, Law CH, Karanicolas PJ, Lin Y, et al. The impact of blood transfusion on perioperative outcomes following gastric cancer resection: an analysis of the American College of Surgeons National Surgical Quality Improvement Program database. Can J Surg. 2016; 59:322-9.

30. Carson JL, Terrin ML, Noveck H, Sander DW, Chaitman BR, Rhoads GG, et al. Liberal or restrictive transfusion in high risk patients after hip surgery. N Engl J Med. 2011; 365:2453-62.

31. Mazer CD, Whitlock RP, Fergusson DA, Hall J, Belley-Cote E, Connolly $\mathrm{K}$, et al. Restrictive or liberal red-cell transfusion for cardiac surgery. N Eng J Med. 2017; 377:2133-44.

32. Wehry J, Agle S, Philips P, Cannon R, Scoggins CR, Puffer L, et al. Restrictive blood transfusion protocol in malignant upper gastrointestinal and pancreatic resections patients reduces blood transfusions with no increase in patient morbidity. Am J Surg. 2015; 210:1197-204.

33. Noh SH, Park SR, Yang HK, Chung HC, Kim SW, Kim HH, et al. Adjuvant capecitabine plus oxaliplatin for gastric cancer after D2 gastrectomy (CLAISSIC): 5-year follow-up of an open-label, randomized phase 3 trial. Lancet Oncol. 2014; 15:1389-96.

34. Katai H, Ishikawa T, Akazawa K, Isobe Y, Miyashiro I, Oda I, et al. Five-year survival analysis of surgically resected gastric cancer cases in Japan: a retrospective analysis of more than 100,000 patients from the nationwide registry of the Japanese Gastric Cancer Association (2001-2007). Gastric Cancer. 2018; 21:144-54.

35. Sahler J, Grimshaw K, Spinelli SL, Refaai MA, Phipps RP, Blumberg N. Platelet storage and transfusions: new concerns associated with an old therapy. Drug Discov Today Dis Mech. 2011; 8: e9-e14.

36. Subramanian A, Berbari EF, Brown MJ, Allen MS, Alsara A, Kor DJ. Plasma transfusion is associated with postoperative infectious complications following esophageal resection surgery: a retrospective cohort study. J Cardiothorac Vasc Anesth. 2012; 26:569-74. 